\title{
Under water glued stud bonding fasteners for offshore structures
}

\author{
Sebastian Myslicki ${ }^{\text {a, }}$, Heinrich Kordy ${ }^{\text {a }}$, Marvin Kaufmann ${ }^{\text {a }}$, Romain Créac'hcadec ${ }^{\mathrm{b}}$, \\ Till Vallée ${ }^{a}$ \\ ${ }^{\text {a }}$ Fraunhofer Institute for Manufacturing Technology and Advanced Materials IFAM, Wiener Street 12, Bremen, Germany \\ ${ }^{\mathrm{b}}$ ENSTA Bretagne, 2 Rue François Verny, Brest, France
}

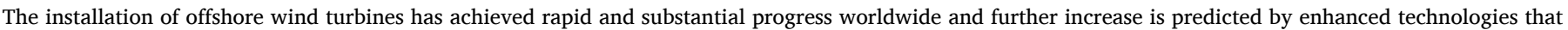

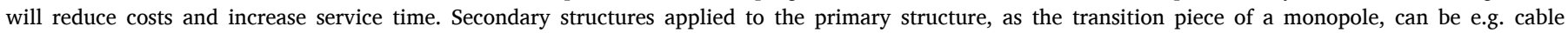

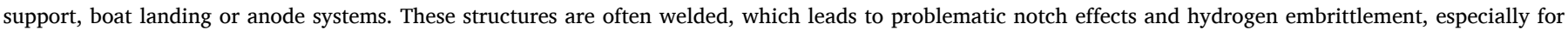

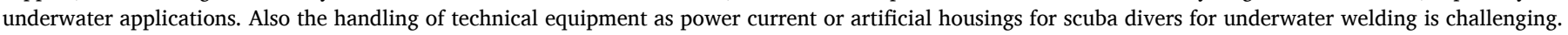

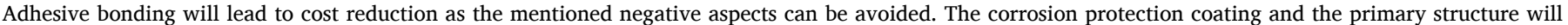

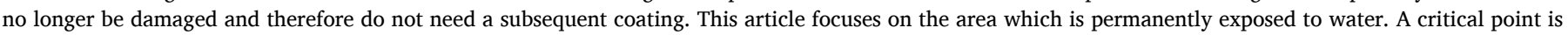

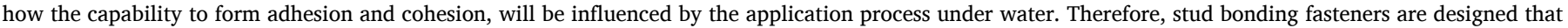

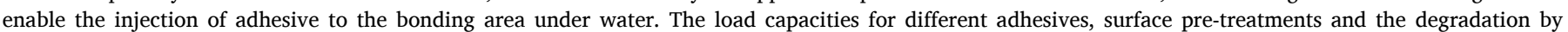

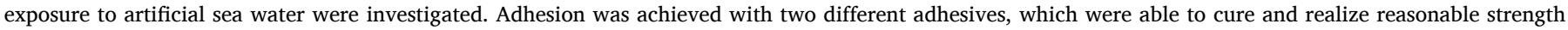
under water. Furthermore, two selected coating systems were able to improve the perfor-mance of the adhesive bond.
\end{abstract}

\section{Introduction}

Due to the considerable development of the offshore wind energy industry in recent years [1-3], especially in Germany and Great Britain [4], the question arises whether load-bearing underwater bonds can further optimize offshore support structures by replacing welded joints. The application of adhesives underwater could also be of interest for the oil and gas extracting industry, as well as for the maritime industry in general.

Traditionally, secondary structures (e.g. ladders, railings, cable ducts, etc.), if they have to be retrofitted under water, are attached to the main supporting structure by welding, bolting or riveting [5]. However, these techniques have major disadvantages: on the one hand, welding under water often achieves an inferior quality of the weld seam, due to the precarious working and environmental conditions (short working intervals, sea currents, darkness, etc.) [6]; much more serious, however, is the effect of residual stresses due to welding [7]. This, in most cases, results in a reduced notch class, and thus a decrease of the fatigue strength. Especially for offshore wind turbines, fatigue strength becomes relevant for the component dimensioning, due to the high number of load cycles caused by wind, waves and sea current. The 1980 collapse of the Alexander L. Kielland Sea Platform [8] - counting 123 fatalities - is acknowledged as one of the most severe accidents caused by material fatigue. Welding a hydrophone to the primary structure initiated a fatigue crack which caused this accident [9]. Furthermore, there is a risk of hydrogen embrittlement, when welding under water. Riveting and bolting have similar impairments. These joining techniques lead to notches on the main load-bearing structure and cause unfavorable local stress peaks. Other methods, such as friction stitch welding or laser welding, are still under development; these can be performed automatically by underwater robots $[6,10]$. But these advanced technologies usually possess the same shortcomings and critical aspects as conventional welding. Mechanical clamping - with clamping pieces - is an alternative to welding, but for geometric reasons it is of limited use and highly impracticable, due to large diameters needed for offshore wind structures.

\footnotetext{
* Corresponding author.

E-mail address: sebastian.myslicki@ifam.fraunhofer.de (S. Myslicki).
} 
Joining under water by adhesively bonded connections is an innovative approach. Adhesives enable the joining of different materials without any thermal input, and ensure uniform stress distributions along the bond. They also offer more design possibilities and are often more economical [11]. But can adhesives also be used under water? According to Allen [12], "water and adhesives are in conflict". According to Waite [11], there are four pathways by which water undermines the performance of adhesive bonds:

- the presence of water as a weak boundary layer at interfaces,

- the wicking or crazing of water into interfaces,

- the hydrolysis or erosion of adhesive and

- the swelling or plasticization of adhesive by water absorption, see Fig. 1

Paradoxically, there are a lot of organisms that live under water and which are able to attach themselves to various surfaces by adhesively bonding. For example, mussels are confronted to the same challenges as adhesive engineers. The mollusks are able to use their foot to prepare the surface for bonding, dispend an adhesive to the surface, displace the water and control its curing [11]. In this paper, the technique used by mussels is interpreted and followed in an engineering manner, in order to master the challenge of bonding under water. Therefore, suitable adhesives, coating systems and substrates are selected and described. Afterwards a typical joint-type will be experimentally investigated with regard to strength and fracture behavior.

Until now, only limited examples of engineering applications of underwater adhesives have been scientifically investigated. In most cases the application was limited to the reinforcement or repairing of underwater structures. J.-H. Jay Kim et al. developed an underwater adhesive for reinforcing and repairing concrete structures under water [13]. This adhesive achieved almost the same strength under water as in a dry environment. According to Ref. [14] it has been proven to be effective to repair underwater pipelines with FRP. The repair can be carried out under water and has proven to be very durable. As well the overall structural performance could be improved by the reinforcement with composite materials [15].

For offshore steel structures, a distinction is made between three different water exposure zones: the splash zone, the intermediate zone and the underwater zone. These three zones experience different levels of corrosion risk [16]; depending on the zone considered, different approaches for the protection against corrosion are put into practice. Possibilities range from coatings for corrosion protection, to cathodic corrosion protection with external current or sacrificial anodes [16,17]. These are well suited for the intermediate zone and the splash zone as well. In Refs. [18,19] different coating systems were investigated and exposed for three years to real conditions in the North Sea. All samples met the requirements for offshore ageing in terms of adhesion. Furthermore, the abrasion resistance of organic corrosion protection

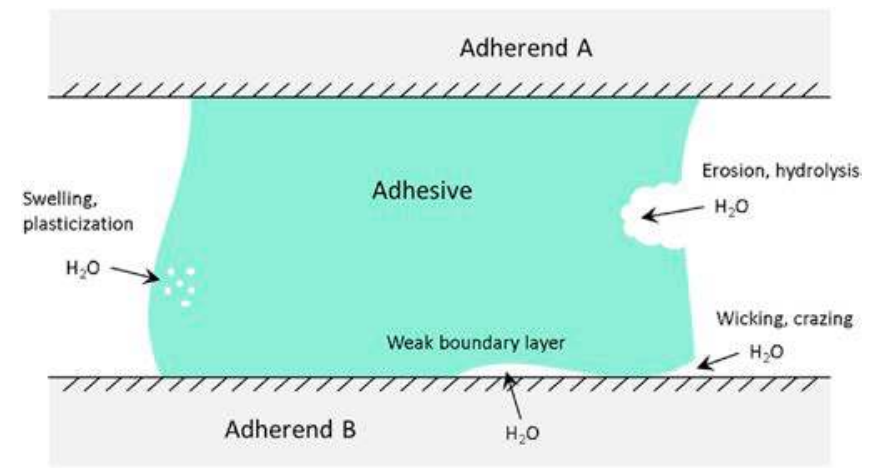

Fig. 1. Four pathways by which water undermines the performance of adhesive bonds, redrawn from Ref. [11]. coating systems was investigated in Ref. [20] and it was found that the coating thickness decreases linearly with the number of abrasion cycles. It was although found that the abrasion resistance increases at low temperatures.

\section{Materials and methods}

\subsection{Materials}

\subsubsection{Adhesives}

Two adhesives with different properties were selected for bonding under water. On the basis of their data sheet and further investigations the adhesives can be described as follows:

- Sika AnchorFix ${ }^{\circledR-3+}$, hereinafter called AnchorFix, is a stiff twocomponent epoxy resin adhesive (2K-EPX). AnchorFix is used for anchoring steel reinforcement in new buildings and conversions, as well as for gluing threaded steels into different materials. According to the data sheet, the pot life (at $25^{\circ} \mathrm{C}$ ) is about $15 \mathrm{~min}$. The adhesive can also be processed at low temperatures, down to $5{ }^{\circ} \mathrm{C}$. The compressive strength (after curing 7 days at $23^{\circ} \mathrm{C}$ ) is $114 \mathrm{MPa}$.

- SikaForce ${ }^{\circledR}-7888$ L10, hereinafter called SikaForce, is an elastic twocomponent polyurethane adhesive (2K-PUR). SikaForce is suitable for structural joints and dynamic loading. It is a fast curing adhesive with a pot life (at $25{ }^{\circ} \mathrm{C}$ ) of $10 \mathrm{~min}$. The processing temperature is between $15{ }^{\circ} \mathrm{C}$ and $30{ }^{\circ} \mathrm{C}$. According to the data sheet, tensile strength (according to ISO 527) is about $20 \mathrm{MPa}$ with an elongation at failure of $40 \%$; lap shear strength (on steel substrates, according to DIN EN 1465) is $20 \mathrm{MPa}$. In addition, a glass transition temperature of $40{ }^{\circ} \mathrm{C}$ was specified.

In order to study the effect of temperature on the mechanical behavior of the adhesive, a Dynamic Mechanical Analysis (DMA) was performed on both adhesives. Besides bulk cured under normal air-cured conditions $\left(21^{\circ} \mathrm{C}, 50 \%\right.$ relative humidity), water-stored (for 14 days at $21{ }^{\circ} \mathrm{C}$ ) and water-cured (water temperature also $21^{\circ} \mathrm{C}$ ) samples were investigated; results are presented in Figs. 2 and 3.

The glass transition temperature $\left(\mathrm{T}_{\mathrm{g}}\right)$ of AnchorFix is above the temperatures which are relevant in the North Sea $\left(0{ }^{\circ} \mathrm{C}-20{ }^{\circ} \mathrm{C}\right.$, acc. to $\mathrm{BSH}$, the Federal Maritime and Hydrographic Agency), irrespective of the storing and curing conditions and is therefore not critical, see Fig. 2. However, this is not the case with SikaForce: the water-cured samples lead to a glass transition temperature of $18.7^{\circ} \mathrm{C}$, which is therefore within a relevant temperature range for the North Sea, as shown by Fig. 3. Thus, the glass transition temperature is reduced by curing and storing under water. The glass transition temperature of $40{ }^{\circ} \mathrm{C}$ given in the data sheet (air-cured) is approximately the same as measured here

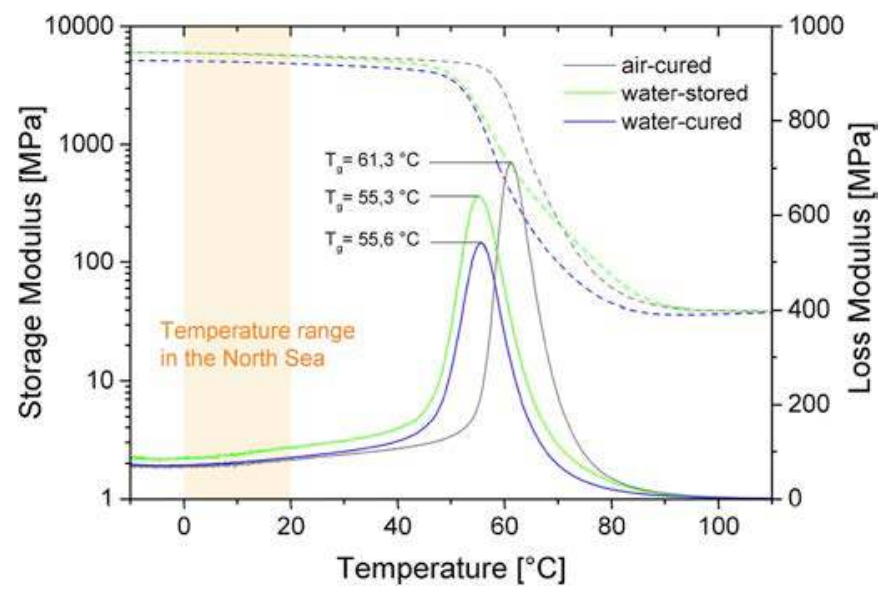

Fig. 2. DMA of AnchorFix (2K-EPX). 


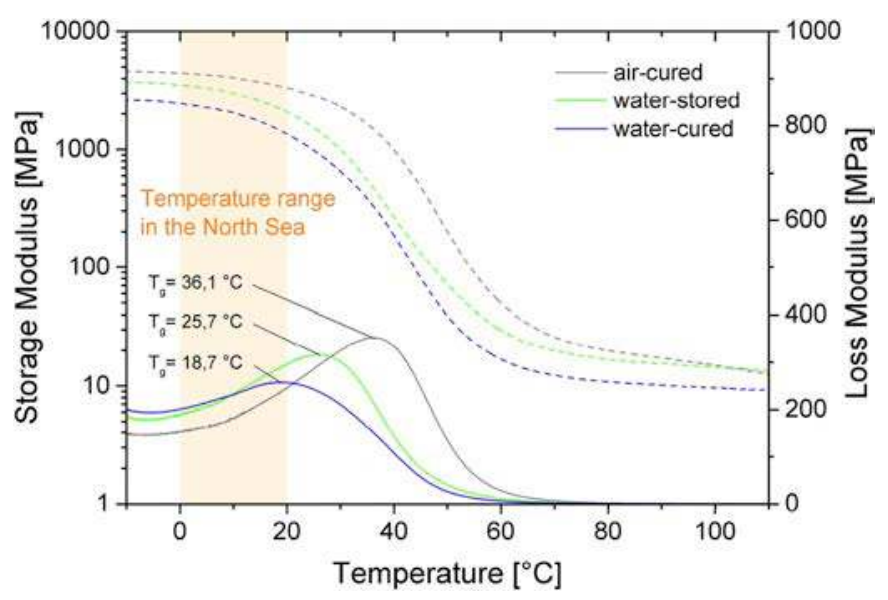

Fig. 3. DMA of SikaForce (2K-PUR).

$\left(36.1^{\circ} \mathrm{C}\right)$.

Subsequently, water absorption by the adhesives was investigated. For this purpose air-cured adhesive samples (square, $60 \mathrm{~mm} \times 60 \mathrm{~mm}, 1$ $\mathrm{mm}$ thick) with a defined initial weight in accordance with ISO 62:2008 were stored in distilled water. Using a precision balance (accuracy $\pm 0.01 \mathrm{mg}$ ), the weight increase (and thus the water absorption) of the samples were measured after various periods of time, as shown in Fig. 4.

The results of the water absorption tests showed that the 2K-PUR absorb more water than the 2K-EPX during the same time. In addition, the samples were not completely saturated with water yet, even after about 125 days of continuous exposure.

\subsubsection{Coatings}

Two coatings of the company Hempel, which are already used in the offshore sector, were considered. Their principal properties, according to the data sheet as well as further investigations, are listed below.

- Hempadur Multi-Strength 35840, short H35840, is a solvent-free, twocomponent polyamine adduct cured epoxy resin paint (2K-EPX) reinforced with glass fibers. The coating completely cures within 7 days at $20^{\circ} \mathrm{C}$. It is stiff and resistant to abrasion, seawater and fresh water.

- Hempadur 35620, short H35620, is a two-component, solvent-free, polyamine adduct cured epoxy paint that cures to a stiff coating with good resistance to seawater and fresh water. It can also be used on components exposed to highly corrosive environments. The coating cures after 7 days at $20^{\circ} \mathrm{C}$.

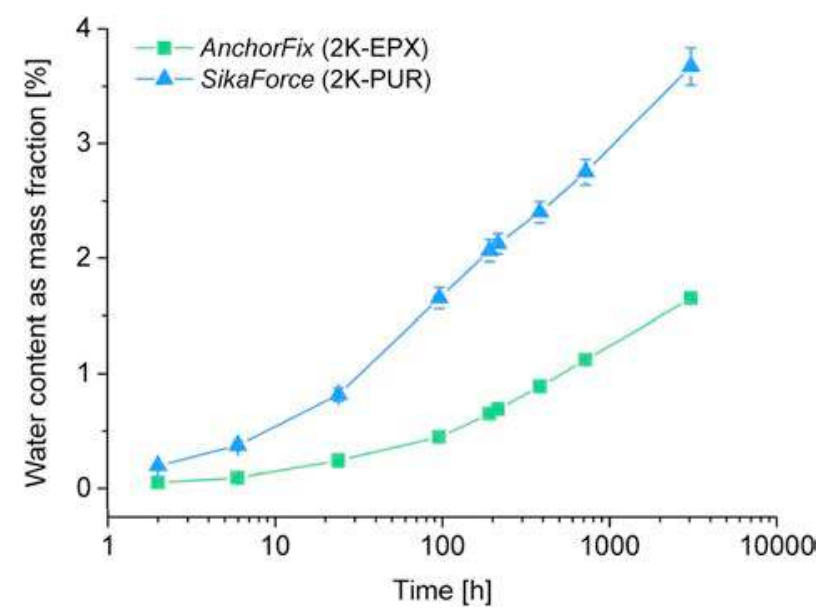

Fig. 4. Water absorption of the used adhesives, average of three samples.
Since fasteners should be bonded directly onto the coatings later, it is important to determine the strength of the coating itself, in order to obtain the possible upper bonding limit of the substrate. The strength of the two coatings was determined using a so-called Pull-off test (acc. to ISO 4624:2016). For that purpose, aluminum cylinders (diameter 20 $\mathrm{mm}$ ) were bonded to the coated steel plates, using a high-strength adhesive (Araldite ${ }^{\circledR} 2014$, EPX). The cylinder was then pulled from the coated steel surface, using an adhesion tester (Elcometer 510), as shown in Fig. 5. In order to obtain a statement about an upper limit of the bonding strength, six replicates per coating were carried out. In all tests the coating failed cohesively. As a result, mean strengths of $17.5 \mathrm{MPa}$ for $H 35840$ and $19.3 \mathrm{MPa}$ for $H 35620$ could be determined, as shown in Fig. 6.

\subsubsection{Adherends}

The parts to be joined are stud bonding fasteners and steel, which are described in more detail as follows. The stud bonding fasteners consist of a circular plate (material 1.4371, stainless steel, diameter $50 \mathrm{~mm}$ ). Two holes were drilled into the plate for adhesive application and drainage of water and adhesive. The hole used for drainage is smaller as the hole through which the adhesive is applied, as shown in Fig. 7. This is supposed to create certain pressure during application so that the adhesive slowly and evenly fills the adhesive gap. A $50 \mathrm{~mm}$ long thread (M10) is welded in the middle and orthogonal to the circular plate. In addition, there is a $2 \mathrm{~mm}$ wide and $1 \mathrm{~mm}$ high seal, which defines and limits a circular and $1 \mathrm{~mm}$ thick bond line. With a diameter of $46 \mathrm{~mm}$, the adhesive surface is $1662 \mathrm{~mm}^{2}$. A steel (S355) commonly used in offshore applications was used as substrate. The steel plate on which the threaded studs are glued is $500 \mathrm{~mm}$ long, $60 \mathrm{~mm}$ wide and $5 \mathrm{~mm}$ thick.

\subsection{Methods}

\subsubsection{Preparation of the test specimen}

In the first step, the surfaces of the substrates were pretreated in various ways. The surface of the threaded studs to be bonded was cleaned with methyl ethyl ketone, then blasted with corundum and then cleaned again to remove contaminants caused by blasting. The surfaces of the steel plates were pretreated in three different ways. One pretreatment was exactly the same as for the threaded studs (cleaning, blasting, re-cleaning); the other two pre-treatments also started with cleaning, blasting, re-cleaning and complement each other by applying the two coatings described in section 2.1.2. The coatings were applied in layers such that a total layer thickness of $800 \mu \mathrm{m}-840 \mu \mathrm{m}$ was reached.

In the second step, the substrates were bonded together under two different conditions: firstly, under water; secondly, in ambient air. For bonding under water substrates were placed in a container filled with artificial seawater (at $20^{\circ} \mathrm{C}$, according to DIN EN ISO 15711), fixed with magnets and glued directly under the water surface, as illustrated in Fig. 8. The adhesives were expected to displace the water from the

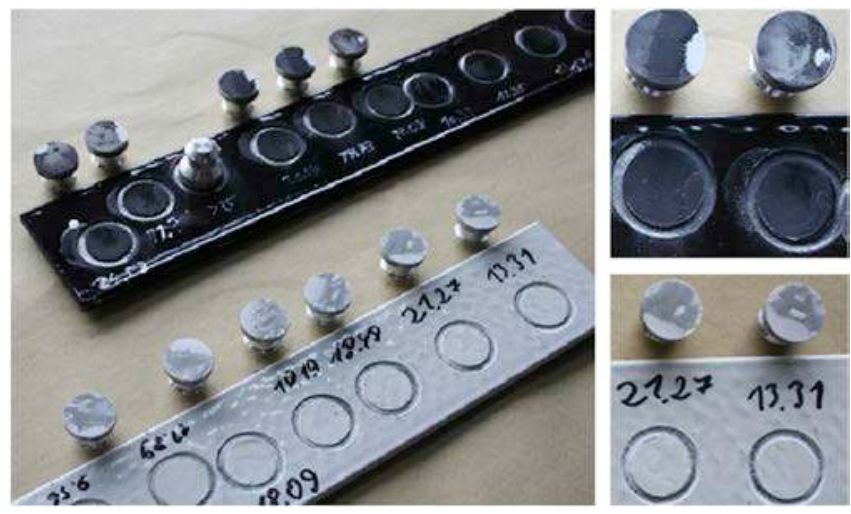

Fig. 5. Fracture pattern of the coatings after head pull test. 


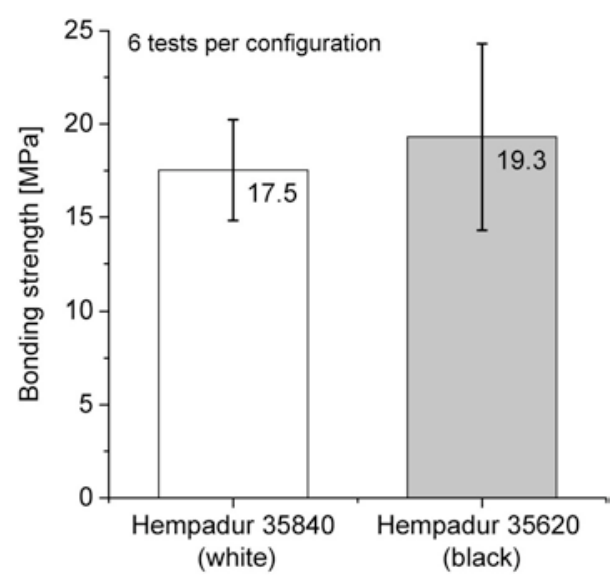

Fig. 6. Bonding Strength of the coatings.

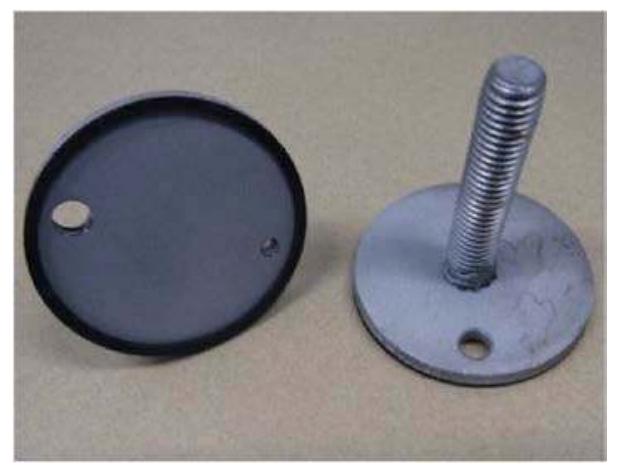

Fig. 7. Stud bonding fastener with seal and ventilation holes.

adhesive gap. The adhesives were processed according to the data sheet. Five threaded studs are glued to each steel plate at a sufficient distance from each other. The samples glued in the air serve as a reference.

Subsequently, in the third step, the glued samples were subjected to three different climate conditions. The air-cured samples are stored for $24 \mathrm{~h}$ under normal conditions $\left(21^{\circ} \mathrm{C}, 50 \%\right.$ relative humidity). A part of the samples glued under water is stored for $24 \mathrm{~h}$ in the artificial sea water (according to DIN EN ISO 15711:2004). The other part of the samples glued under water is also stored in artificial seawater, but for $1000 \mathrm{~h}$. All samples were tensile tested within $15 \mathrm{~min}$ after removal from the water storage to avoid re-drying.

Due to the various surface pretreatments (blasted, $H 35840$ and H35620), adhesives (AnchorFix and SikaForce), storing conditions (24 h air, $24 \mathrm{~h}$ water and $1000 \mathrm{~h}$ water) and a sample size of five, a total of 90
(1)

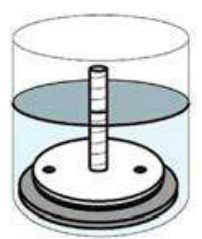

(4)

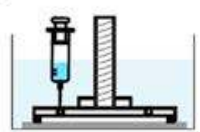

(2)

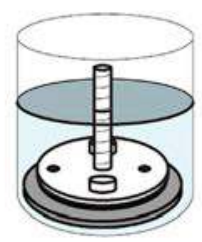

(5)

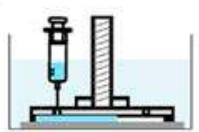

(3)

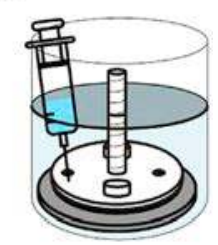

(6)

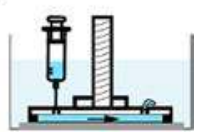

Fig. 8. Under water adhesive application procedure. individual experiments were carried out. These are summarized in six test series, in each of which the load capacity is considered as a function of the adhesive and storing condition for all the surface pre-treatments, as shown in Table 1.

\subsubsection{Experimental setup}

The specimens were tested with a universal testing machine $\left(\mathrm{F}_{\max }=\right.$ $20 \mathrm{kN})$ at room temperature $\left(21^{\circ} \mathrm{C}\right)$. Samples were loaded with a displacement-control at a rate of $5 \mathrm{~mm} / \mathrm{min}$ using a specifically designed rig until failure (pull-compression load), as shown in Fig. 9.

\section{Results}

\subsection{Adhesive AnchorFix (2K-EPX)}

\subsubsection{Load-displacement behavior}

All Load-Displacement curves, apart from the beginning of the load increase, are linear-elastic. The qualitative curve progression cannot be distinguished between the different coatings and storage conditions. The failure occurred abruptly (brittle failure). Samples bonded and stored under water exhibited a significant reduction in stiffness and strength, if compared to the ones bonded and stored in air. However, the displacement at failure is in the same range, as shown in Fig. 10.

\subsubsection{Tensile bonding strength}

The threaded studs glued to the steel plate coated with $H 35840$ achieve the highest strength, when cured in air, followed by the steel plate coated with $H 35620$ and the uncoated substrate, see Fig. 11. Due to curing and storing under water, the strength of the specimen for all surface pretreatments decreases, except for the $H 35620$ coating. This coating also shows a significantly higher standard deviation after $24 \mathrm{~h}$ of water storage. An extended storage in water (for $1000 \mathrm{~h}$ ) leads to a further reduction in strength in the case of the coated systems. Detailed values of the average tensile bonding strength are given in Table 3.

\subsubsection{Fracture pattern}

After $24 \mathrm{~h}$ air-curing, the fracture within the uncoated substrate occurred in the adhesive, the remaining areas have failed close to the surface of the substrate steel and the threaded stud plate. Due to the sample conditioning and curing under water, the fracture pattern changes - the failure only occurs between the substrate and the adhesive (adhesive failure). Furthermore, a slightly reddish surface can be seen, which indicates that the adhesive layer has been "infiltrated" by water and has started to corrode. In the case of the coated substrates, fracture occurs in the adhesive (cohesive failure) and the coating is partially torn off from the steel substrate. In contrast to the uncoated substrates, the fracture pattern of the coated ones is similar for all storage conditions. Again, slightly reddish areas indicating corrosion can be seen in the fracture pattern of the samples aged in water. Typical fracture pattern are shown in Table 2.

\subsection{Adhesive SikaForce (2K-PUR)}

\subsubsection{Load-displacement behavior}

The Load-Displacement curves are mostly linearly-elastic, apart from

Table 1

Overview of the test series.

\begin{tabular}{|c|c|c|c|c|c|c|}
\hline \multirow{2}{*}{$\frac{\text { Adhesive }}{\text { Storage condition }}$} & \multicolumn{3}{|c|}{ AnchorFix } & \multicolumn{3}{|c|}{ SikaForce } \\
\hline & $24 \mathrm{~h}$ & $24 \mathrm{~h}$ & $1000 \mathrm{~h}$ & $24 \mathrm{~h}$ & $24 \mathrm{~h}$ & $1000 \mathrm{~h}$ \\
\hline /coating & Air & Water & Water & Air & Water & Water \\
\hline Blasted Steel & Series & Series & Series & Series & Series & Series \\
\hline Coating $H 35840$ & 1 & 2 & 3 & 4 & 5 & 6 \\
\hline Coating H3562O & & & & & & \\
\hline
\end{tabular}



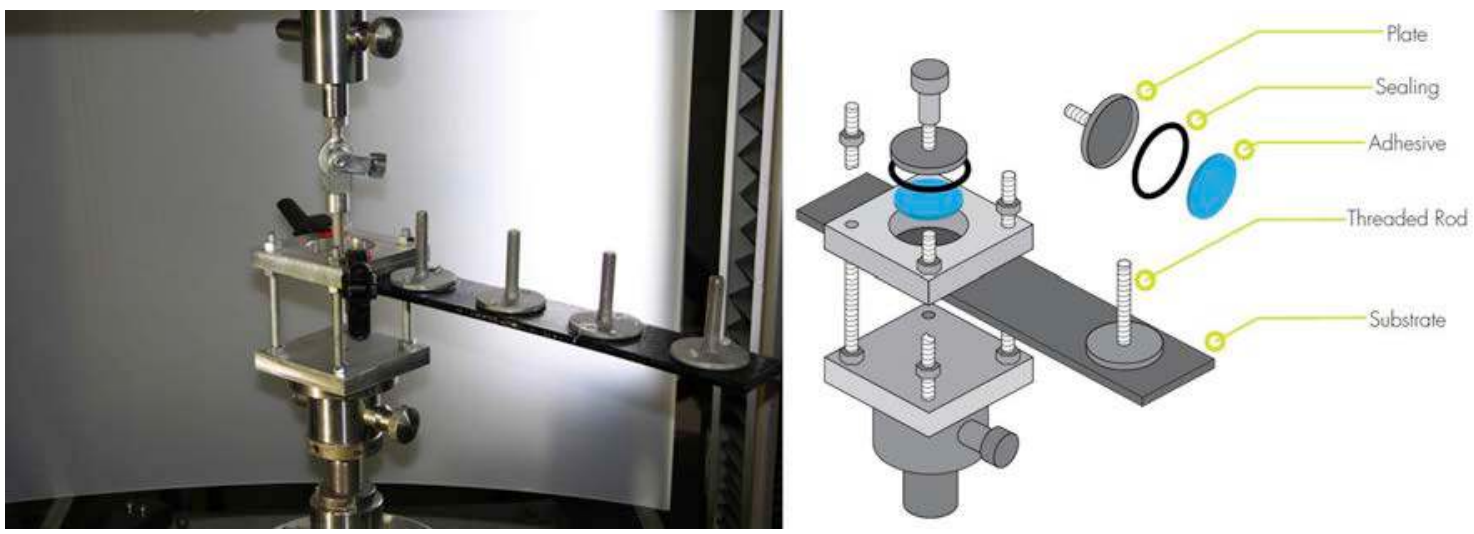

Fig. 9. Experimental setup and specimen structure.

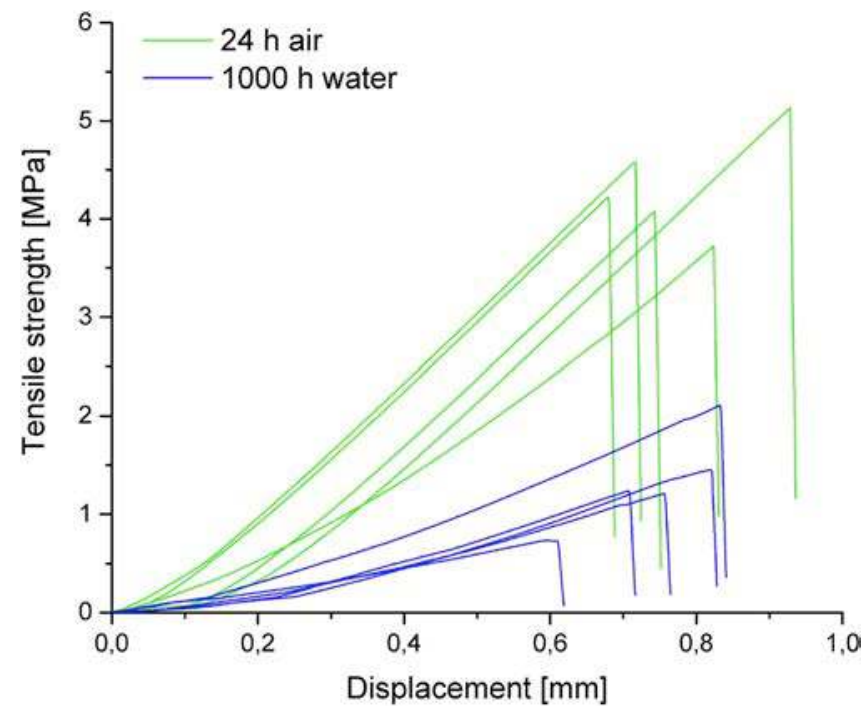

Fig. 10. Typical load-displacement behavior of specimen glued with AnchorFix and steel coated with $H 35620$.

the beginning of the load increase. The qualitative curve characteristics of the different coatings and types of storing were the same. The failure occurs abruptly (brittle failure) as well. It can be seen that with the $H 35840$ coating the stiffness slightly increases after $24 \mathrm{~h}$ under water but the tensile strength remains almost unchanged. However, the displacement at failure becomes smaller, due to the underwater storing, see Fig. 12.

\subsubsection{Tensile bonding strength}

The connector bonded with SikaForce achieves similarly high strength when air-cured, regardless of the coating. The highest strength is achieved with the $H 35620$ coating, the lowest with the uncoated substrate, see Fig. 13. The strength of the $H 35620$ coating decreases slightly, due to storing and curing under water. The coating $H 35840$ even shows an increase in strength after $1000 \mathrm{~h}$ water storage. Strength of the uncoated substrates decreased continuously after $24 \mathrm{~h}$ and $1000 \mathrm{~h}$ water-storage. In Table 3 the average tensile bonding strength of all test configurations are presented.

\subsubsection{Fracture pattern}

The fracture patterns of the samples in which polyurethane adhesive was used, differ significantly from those with epoxy resin adhesive. The uncoated samples show a mixed fracture pattern, consisting of adhesive and cohesive failure. In all samples bonded under water, the polyurethane adhesive is partially foamed. This is typical, as carbon dioxide outgassing occurs as soon as a polyurethane reaction mixture comes into contact with water. The steel substrate is only corroded at the edge of the plate and not under the complete adhesive layer, as it was the case with the 2K-EPX. The fracture patterns of the specimen coated with $H 35840$ are very similar, regardless of the storing condition: the coating adhered to the adhesive in the middle of the plate and the adhesive failed cohesively at the edges. For the H3562O coating, the adhesive failed predominantly cohesively. Typical fracture patterns for the adhesive SikaForce are shown in Table 4.

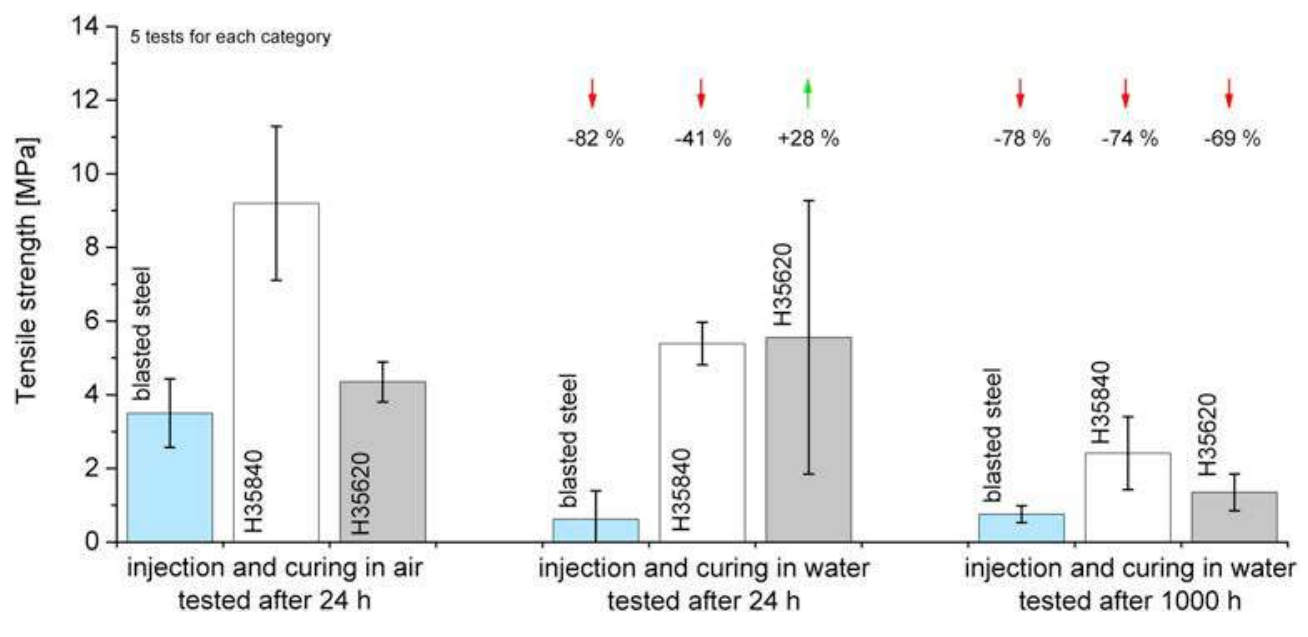

Fig. 11. Tensile Strength for adhesive AnchorFix. 
Table 2

Fracture pattern for different storage conditions and coatings for adhesive AnchorFix with corresponding tensile strength of the specimen shown.

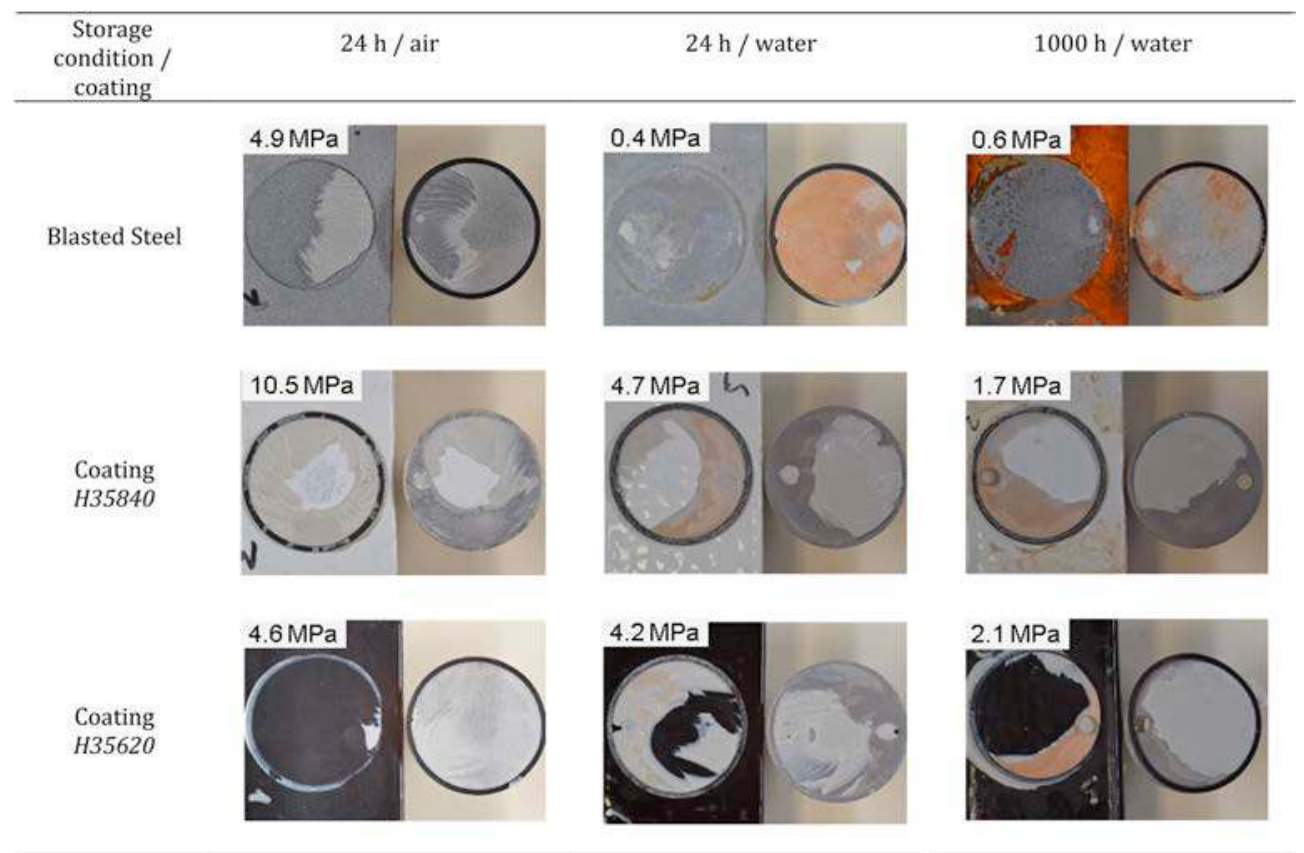

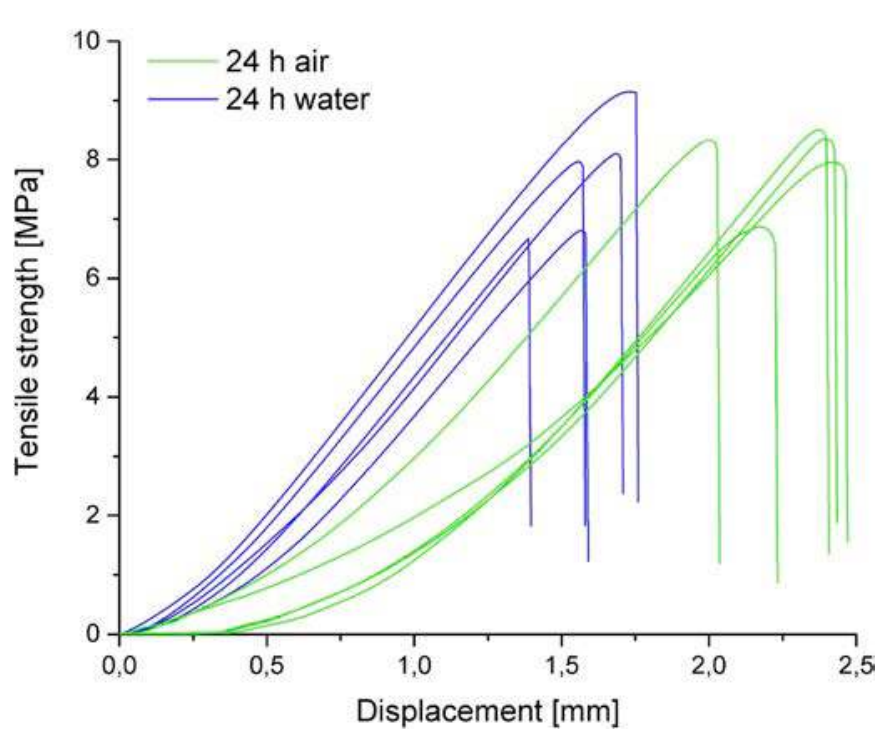

Fig. 12. Typical load-displacement behavior of specimen glued with SikaForce and steel coated with $H 35840$.

\section{Discussion}

In order to successfully carry out underwater bonding, adhesives have to meet various requirements. If the water temperature is too low, there is a risk that the adhesives will not cure. However, if the water temperature is too high, the mechanical properties of the adhesive may be reduced, in particular for temperatures exceeding $\mathrm{T}_{\mathrm{g}}$. In the North Sea, temperatures range from a minimum of $0{ }^{\circ} \mathrm{C}$ to a maximum of $20^{\circ} \mathrm{C}$ average water temperature between winter and summer, according to BSH (The Federal Maritime and Hydrographic Agency). The minimal processing temperature of the adhesives used here is $+5{ }^{\circ} \mathrm{C}$ (AnchorFix) and $+15{ }^{\circ} \mathrm{C}$ (SikaForce), which restricts their use to certain seasons, at least without a tempering process. It has been observed that the glass transition temperature and the relative stiffness are reduced by storing and curing under water. This is not critical for the AnchorFix adhesive, since the glass transition temperature was reduced from $61.3^{\circ} \mathrm{C}$ (aircured) to $55.6{ }^{\circ} \mathrm{C}$ (water-cured), and is thus still significantly higher than the temperatures occurring in the North Sea. However, this is not the case with the SikaForce adhesive. Here, the glass transition temperature is reduced from $36.1{ }^{\circ} \mathrm{C}$ (air-cured) to $18.7^{\circ} \mathrm{C}$ (water-cured) which could be problematic in service. As a result, the relative stiffness of the adhesive at temperatures of about $20^{\circ} \mathrm{C}$ is reduced to about one third of the reference value simply by curing under water. At this point, however, it should be noted that the 2K-PUR adhesive (SikaForce), which has a lower stiffness, has achieved higher tensile strengths than the stiffer 2K-EPX adhesive (AnchorFix). However, how the glass transition temperature and stiffness under water develop over a longer period of time (beyond 14 days) remains an open question, as none of both adhesives had fully saturated with water after 125 days of storing.

The different coating systems result in higher tensile strength for both adhesives, and under all storage conditions, if compared to the uncoated steel substrate. The fracture patterns indicate that better adhesion is also achieved by the use of coatings. The failure of the specimens without coating occurs predominantly between the steel substrate and the adhesive. The failure pattern in the coated specimens is predominantly classified as mixed fracture or cohesive fracture, in some cases the coating is even torn out by the adhesive. The coatings also cause less or no corrosion in the adhesive joint.

The results have shown that adhesive bonding under water is feasible, and that it might represent a good alternative to commonly used joining techniques. During injection, the adhesive displaced most of the water from the adhesive joint. This has been observed by a specially manufactured, transparent threaded stud made of PMMA, as demonstrated in Fig. 14. With AnchorFix, however, air and water inclusions were partially visible in the fracture pattern, especially at the edges. This phenomenon can be explained by the lower viscosity of the 2K-EPX adhesive. SikaForce markedly foamed under water. Both considered adhesives are able to generate adhesion to the substrates and 


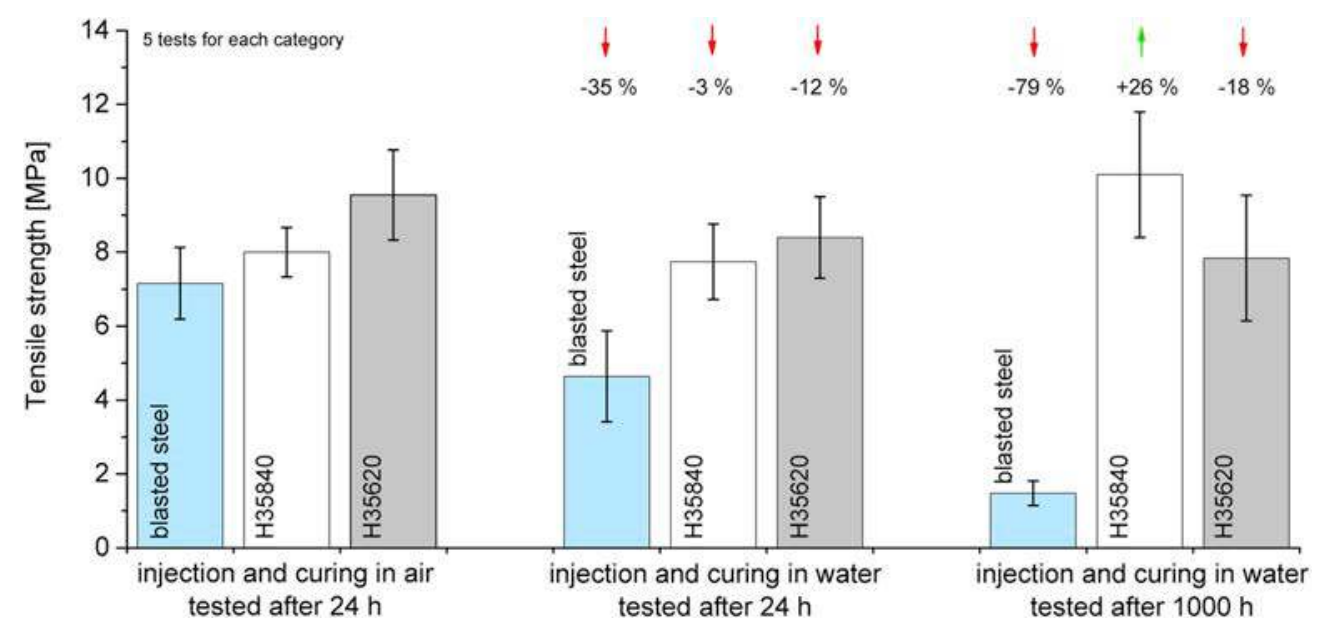

Fig. 13. Tensile Strength for adhesive SikaForce.

Table 3

Average tensile bonding strength $[\mathrm{MPa}]$.

\begin{tabular}{|c|c|c|c|c|c|c|c|c|c|c|c|c|}
\hline Adhesive & \multicolumn{6}{|c|}{ AnchorFix (2K-EPX) } & \multicolumn{6}{|c|}{ SikaForce (2K-PUR) } \\
\hline Storage condition & $24 \mathrm{~h}$ & & $24 \mathrm{~h}$ & & $1000 \mathrm{~h}$ & & $24 \mathrm{~h}$ & & $24 \mathrm{~h}$ & & $1000 \mathrm{~h}$ & \\
\hline /coating & Air & & Water & & Water & & Air & & Water & & Water & \\
\hline Blasted Steel & 3,5 & $\pm 0,9$ & 0,6 & $\pm 0,8$ & 0,8 & $\pm 0,2$ & 7,2 & $\pm 1,0$ & 4,6 & $\pm 1,2$ & 1,5 & $\pm 0,3$ \\
\hline Coating H35840 & 9,2 & $\pm 2,1$ & 5,4 & $\pm 0,6$ & 2,4 & $\pm 1,0$ & 8,0 & $\pm 0,7$ & 7,7 & $\pm 1,0$ & 10,1 & $\pm 1,7$ \\
\hline Coating $H 35620$ & 4,4 & $\pm 0,5$ & 5,6 & $\pm 3,7$ & 1,4 & $\pm 0,5$ & 9,6 & $\pm 1,2$ & 8,4 & $\pm 1,1$ & 7,8 & $\pm 1,7$ \\
\hline
\end{tabular}

Table 4

Fracture pattern for different storage conditions and coatings for adhesive SikaForce with corresponding tensile strength of the specimen shown.

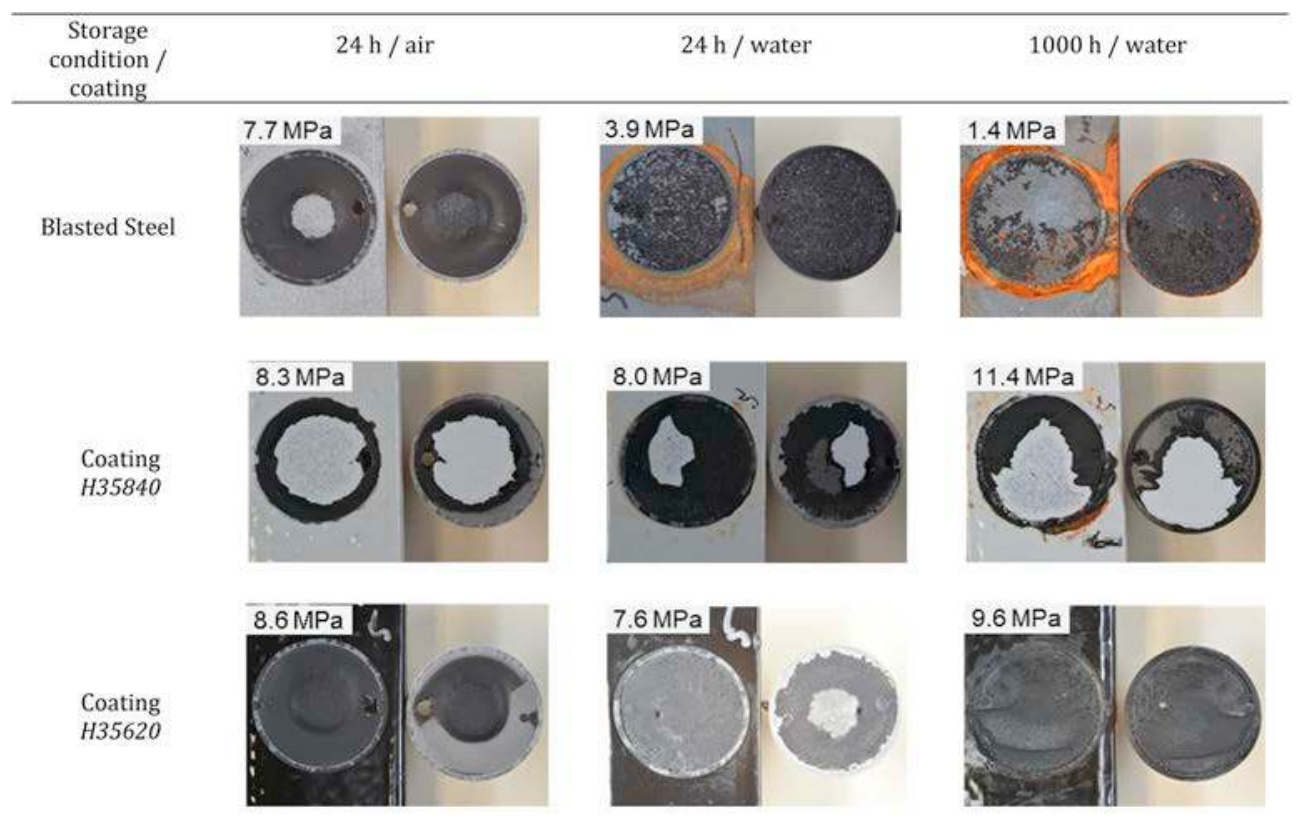

cure under water.

\section{Conclusions}

In this paper, the process of adhesive bonding under water was investigated considering two adhesives: a $2 \mathrm{~K}-\mathrm{EPX}$, and a $2 \mathrm{~K}-\mathrm{PUR}$ adhesive. The surfaces to be bonded were steel, coated with two common coating systems for offshore structures, and compared to uncoated steel used as a reference. Samples were glued both under water and in the air, and different time durations of storing times under water were considered to validate their influence on the load capacity. These parameters resulted in an experimental program with a total of 90 experiments from which the following conclusions can be drawn: 


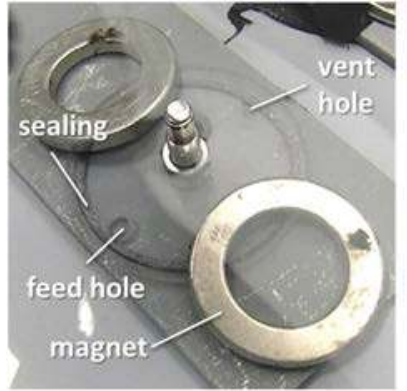

(a)

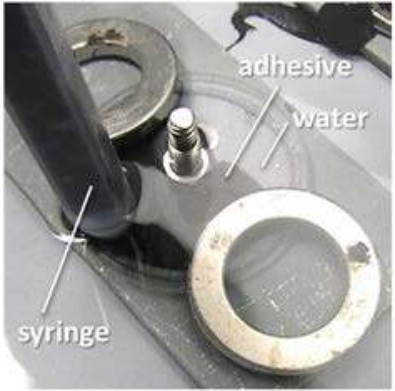

(b)

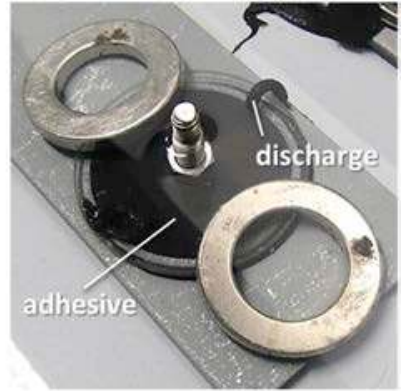

(c)

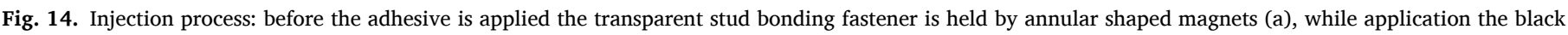
adhesive continuously displaces the water (b), after application the adhesive completely displaced the water and reached the vent hole (c).

- When the adhesive was injected under water, the water was almost completely displaced by the adhesive from the adhesive gap. The tested adhesives were able to cure under water and build up adhesion to the substrate surfaces.

- The glass transition temperature $\left(\mathrm{T}_{\mathrm{g}}\right)$ of both adhesives was reduced by storing and curing under water. Both adhesives absorb water over time. However, full water saturation could not be determined after 125 days.

- The 2K-PUR adhesive achieved higher strengths and thus proved to be more resistant for underwater applications. It should be noted that the glass transition temperature of the 2K-PUR adhesive can become very low $\left(\mathrm{T}_{g}=18.7{ }^{\circ} \mathrm{C}\right.$ when cured under water) and is therefore within a relevant temperature range of the North Sea.

- Independently of the adhesive used, the coatings lead, both under water and in the air, to a higher strength of the bond. The coatings also reduced the occurrence of corrosion and in some cases prevented it completely.

The experiments described within this paper have demonstrated the general feasibility of joining under water by adhesively bonding. Further investigations are required to ensure that stud bonding fasteners can be successfully bonded to offshore structures under water so that structural loads can be transferred to the main structure. Since these bonding fasteners are not only subjected to tensile stress but also to shear stress, the mechanical behavior resulting from this type of load must also be investigated. In addition, the use of bonding fasteners in the form of threaded studs, not only under water, but also in the intermediate zone and splash zone could be of interest. The influences of hydrostatic pressure, marine growth and low water temperatures must also be validated in further investigations.

\section{Acknowledgements}

This research was supported by the German Federal Ministry of Economics \& Energy through the German Federation of Industrial Research Associations (AiF) as a part of the program for promoting industrial cooperative research (project IGF $1393 \mathrm{~N}$ of the Research Association for Steel Application - FOSTA). We thank our colleagues T. Marquardt and AW. Momber from Muehlhan AG who provided insight and expertise concerning offshore coatings that greatly assisted the research.

\section{References}

[1] Kaldellis JK, Kapsali M. Shifting towards offshore wind energy—recent activity and future development. Energy Policy 2013;53:136-48.

[2] Sun X, Huang D, Wu G. The current state of offshore wind energy technology development. Energy 2012;41(1):298-312.

[3] Green R, Vasilakos N. The economics of offshore wind. Energy Policy 2011;39(2): 496-502.

[4] Kern F, Smith A, Shaw C, Raven R, Verhees B. From laggard to leader: explaining offshore wind developments in the UK. Energy Policy 2014;69:635-46.

[5] Dolez PI, Williams C, Goff A, Love BJ. Properties of photopolymerisable acrylic adhesives for underwater bonding. J Soc Underw Technol 2003;(25):199-208.

[6] Greek D. In-depth answer to problem welds. thirteenth ed. Professional Engineering; 2000.

[7] Dürr A. Zur Ermüdungsfestigkeit von Schweißkonstruktionen aus höherfesten Baustählen bei Anwendung von UIT-Nachbehandlung. Universität Stuttgart; 2007.

[8] Moan T. Life cycle structural integrity management of offshore structures. Struct Infrastruct Eng 2018;14(7):911-27.

[9] Norwegian Ministry of Justice Police. The Alexander L. Kielland accident: report of a Norwegian public commission appointed by royal decree of March 28. Oslo, Norway. 1980.

[10] Shannon GJ, Deans WF, Watson J. Subsea laser welding in the offshore oil industry. Underw Technol 1994;(20):9-13.

[11] Waite JH. Nature's underwater adhesive specialist. Int J Adhesion Adhes 1987;7 (1):9-14.

[12] Allen KW. Symposium on water and adhesion. London, UK: The City University; 1982.

[13] Kim SB, Yi NH, Phan HD, Nam JW, Kim J-HJ. Development of aqua epoxy for repair and strengthening of RC structural members in underwater. Constr Build Mater 2009;23(9):3079-86.

[14] Shamsuddoha M, Islam MM, Aravinthan T, Manalo A, Lau K-t. Effectiveness of using fibre-reinforced polymer composites for underwater steel pipeline repairs. Compos Struct 2013;100:40-54.

[15] Seica MV, Packer JA. FRP materials for the rehabilitation of tubular steel structures, for underwater applications. Compos Struct 2007;80(3):440-50.

[16] Momber A, Plagemann P, Stenzel V, Schneider M. Beurteilung von korrosionsschutzsystemen für offshore-windenergietürme - Teil 1: problemstellung und versuchsdurchführung. Stahlbau 2009;78(4):259-66.

[17] Momber A, Plagemann P, Stenzel V, Schneider M. Beurteilung von korrosionsschutzsystemen für offshore-windenergietürme - Teil 2: ergebnisse und schlussfolgerungen. Stahlbau 2009;78(6):394-401.

[18] Momber AW, Plagemann P, Stenzel V. The adhesion of corrosion protection coating systems for offshore wind power constructions after three years under offshore exposure. Int J Adhesion Adhes 2016;65:96-101.

[19] Momber AW, Plagemann P, Stenzel V. Performance and integrity of protective coating systems for offshore wind power structures after three years under offshore site conditions. Renew Energy 2015;74:606-17.

[20] Momber AW, Irmer M, Glück N, Plagemann P. Abrasion testing of organic corrosion protection coating systems with a rotating abrasive rubber wheel. Wear 2016;348-349:166-80. 